\title{
Educação e desenvolvimento econômico no Brasil
}

LÚCIA BRUNO

Universidade de São Paulo

\section{INTRODUÇÃO}

A relação entre educação e desenvolvimento econômico não é, de forma alguma, linear e para discuti-la cabe tecer algumas considerações preliminares. Quando Marx analisa a circulação e a reprodução do capital, no volume II de sua obra O Capital, ele nos mostra como essa reprodução envolve também a reprodução das classes sociais. No que se refere à classe trabalhadora, reproduzi-la implica manter em condições de trabalhar não só os que estão na ativa, mas aqueles que se encontram no exército de reserva, e mais, implica produzir as novas gerações para que o circuito do capital não se interrompa.

Nessa perspectiva, reproduzir a classe trabalhadora envolve, para além do trabalho assalariado, que lhe garante parte da sobrevivência, o trabalho realizado fora das empresas, tais como as atividades desempenhadas no âmbito da família (trabalho doméstico não pago), nos hospitais que garantem a saúde do trabalhador, nas instituições de lazer e de consumo, que além de lhe proporcionar a reposição de suas energias ainda operam como instâncias formativas, e a escola, que atua diretamente na produção das qualificações necessárias para o exercício do trabalho. 
Essa perspectiva do processo de reprodução da classe trabalhadora globalmente considerada amplia o entendimento do que seja local de trabalho no capitalismo, já que inclui atividades produtivas realizadas nas mais diversas instituições. Consequentemente permitiu a autores como Tronti (1973) e Cleaver (1981), referências neste artigo, falarem em fábrica social para se referirem à sociedade capitalista.

O processo de reprodução da classe trabalhadora global e da composição do proletariado como constituído por trabalhadores da fábrica e de fora dela, assim como da sociedade como o local dessa reprodução, indica uma nova dimensão do capitalismo até recentemente, não propriamente ignorada, mas pouco problematizada. Trata-se da expansão dos mecanismos econômicos do capitalismo para o conjunto das instituições sociais, colocando em evidência a dimensão política do capital, na medida em que impor o trabalho nas mais diversas esferas sociais é estender sobremaneira o controle do capital sobre todos os que só podem sobreviver colocando sua capacidade de trabalho a serviço de outrem.

Para compreendermos a importância da educação nesse vasto processo de reprodução da classe trabalhadora e, ao mesmo tempo, do capital, temos de inseri-la na relação da mais-valia, o que nos vai permitir estabelecer sua relação com o desenvolvimento econômico.

\section{EDUCAÇÃO NOS MECANISMOS GERAIS DA ACUMULAÇÃO DE CAPITAL}

No século XIX, quando Marx escreveu sua obra, o tempo que os trabalhadores passavam fora da fábrica era tão reduzido e voltado para a pura reposição de suas energias exauridas durante extensas jornadas de trabalho que "não havia necessidade de nenhuma teoria especial sobre a família, o trabalho doméstico ou escolar, porque constituíam uma parte desprezível do dia" (Cleaver, 1981, p. 140).

Por essa razão, o trabalho doméstico foi, durante muito tempo, considerado um trabalho não produtivo. Da mesma forma, o trabalho escolar, tanto do professor quanto do aluno, não era visto como uma atividade que tem seu lugar na reprodução ampliada do capital, uma vez que a escola, nas fases iniciais do capitalismo, tinha pouca importância na formação de trabalhadores.

No entanto, a vitória nas lutas travadas pelos trabalhadores, no século XIX e início do século XX, pela obtenção da fixação/redução da jornada de trabalho e melhores salários levou os capitalistas a recorrerem ao uso crescente da maquinaria, resultando em condensação da jornada, o que resultou em aumento do tempo livre dos trabalhadores.

Rapidamente, os capitalistas procuraram criar meios de controlar esse tempo vivido fora dos locais de trabalho para convertê-lo também em tempo de 
trabalho: trabalho produtivo voltado para a reprodução da força de trabalho. Em consequência, tanto o lazer quanto o trabalho doméstico e o escolar passaram por reorganizações sucessivas.

No que se refere à educação escolar, o que se observa é que quanto mais se expandia, incluindo camadas mais vastas da classe trabalhadora, mais aumentava sua subordinação ao controle do capital. Não só se instituiu a obrigatoriedade da matrícula de crianças e jovens em idade escolar, como as escolas sob o controle dos trabalhadores, especialmente as de orientação libertária e anarquista, foram rapidamente fechadas e algumas vezes violentamente reprimidas pelos poderes constituídos. Era fundamental que o controle da produção de capacidade de trabalho ficasse sob o domínio do capital mediatizado pelo Estado. Assim, a educação dita pública foi condicionada, não para o desenvolvimento da inteligência e da autonomia intelectual dos filhos de trabalhadores, mas para atender às necessidades de determinadas especialidades, da nova tecnologia, das novas estratégias de controle social e, acima de tudo, das necessidades oriundas do novo quadro disciplinar que se tornou dominante (Cleaver, 1981; Bernardo, 1985; Bruno, 1996).

Os sistemas nacionais de educação foram, então, criados a partir dos modelos burocráticos vigentes, inspirados, de início, na teoria clássica da administração para, em seguida, serem reorganizados ao longo do século XX, tendo como referência os sucessivos modelos de gestão e administração empresarial.

Dessa forma, os professores e outros profissionais da educação passaram a ter seu trabalho regido pela Lei do Valor, tendo em vista manter baixo o valor força de trabalho em processo de formação. Esses profissionais são, na perspectiva aqui adotada, trabalhadores produtivos, no sentido que lhes conferiu Marx no capítulo 16 do volume I de O Capital: "Para trabalhar produtivamente, já não é necessário ao próprio indivíduo colocar sua mão no objeto; é suficiente que ele seja um órgão do trabalhador coletivo e desempenhe qualquer uma de suas funções subordinadas" (Marx, 1976, p. 135).

\section{A EDUCAÇÃO NA DINÂMICA DA MAIS-VALIA ABSOLUTA E DA MAIS-VALIA RELATIVA}

Vejamos a seguir como a educação se insere na dinâmica da mais-valia, entendida como resultante da troca desigual de tempos de trabalho: tempo de trabalho despendido durante a jornada de trabalho; tempo de trabalho necessário à reprodução do trabalhador. Ou seja, a mais-valia resulta da capacidade do trabalhador de despender, durante o processo de realização de suas atividades produtivas, um tempo de trabalho superior ao que tem em si incorporado. Essa capacidade, no entanto, não é garantia de que a desigualdade na troca de tempos de trabalho ocorrerá. Depende do trabalhador, pois, como a exploração é uma relação social 
estruturada no e pelo conflito entre as classes, não se tem nunca a garantia de que o trabalho excedente será produzido. Por conflito, temos de entender não só as lutas coletivas, mas também formas individuais de revolta e resistência, porque, indiferente às formas que assume, seu resultado é sempre uma redução do tempo de trabalho excedente.

Os capitalistas, por sua vez, procuram permanentemente reduzir o tempo de trabalho necessário à reprodução da força de trabalho, ou aumentar o tempo por ela despendido durante o processo de trabalho, procurando, dessa forma, aumentar a desigualdade na troca de tempos de trabalho. Daí ser o conflito o elemento estruturante do processo de trabalho, e não há teoria administrativa ou técnica de gerenciamento do trabalho que não o leve em consideração (Bruno, 1996, p. 105).

Para garantir a reprodução dessa defasagem e o seu acréscimo permanente, o capitalista recorre a diversos mecanismos que incidem diretamente sobre a formação da força de trabalho. Para explicar essa incidência, devemos compreender os mecanismos da mais-valia tanto absoluta quanto relativa, além da diferença entre aumento de produção e aumento de produtividade.

Quando o tempo de trabalho excedente aumenta em decorrência da extensão do tempo de trabalho despendido pelos trabalhadores (extensão da jornada), o resultado cresce apenas porque, durante um período mais longo de atividade, foram produzidas mais unidades, mantendo-se, no entanto, o valor de cada uma inalterado. Nesse caso, a exploração agrava-se sem que aumente a produtividade, pois se trata de uma situação em que os capitalistas se limitam a obrigar os trabalhadores a operarem durante mais tempo os mesmos instrumentos e maquinaria, mantendo-se o mesmo sistema de organização do trabalho. No caso da intensificação da jornada, trata-se de eliminar os tempos não produtivos ou, como Marx os denominou, os tempos mortos, comprimindo-os, aumentando o tempo de trabalho e, consequentemente, a quantidade de mercadorias produzidas. O importante a sublinhar nessa situação característica da mais-valia absoluta é que o aumento da produção em decorrência do aumento do tempo de trabalho realizado não implica qualquer alteração na qualificação dos trabalhadores.

Situação bem diferente é a da exploração a partir dos mecanismos da mais-valia relativa. Nesse caso, o aumento do tempo de trabalho excedente é obtido por meio da diminuição do valor incorporado nos bens e serviços consumidos pelos trabalhadores, o que permite a redução do tempo necessário destinado à sua reprodução, ampliando-se, portanto, o tempo de trabalho excedente. Mas, para diminuir o valor incorporado nesses bens e serviços, é fundamental introduzir inovações tecnológicas nos setores que os produzem, o que implica remodelações também nas empresas que lhes fornecem maquinário e matérias-primas, serviços de manutenção e infraestrutura em geral, como energia, meios de transporte e comunicação, entre outros. Isso significa que é preciso haver inovações em cadeia para que os ganhos de produtividade se efetivem. 
Trata-se, portanto, de introduzir remodelações técnicas e organizacionais gerais que permitam o crescimento do número de bens e serviços produzidos numa mesma fração de tempo, diminuindo, consequentemente, o tempo de trabalho socialmente necessário para a produção de cada unidade, desencadeando o aumento da produtividade. Ou seja, esse aumento diz respeito à elvação da quantidade de bens e serviços produzidos numa mesma fração de tempo, enquanto o aumento da produção se limita a uma ampliação de unidades produzidas apenas porque houve uma elevação correspondente do tempo trabalhado.

Tanto em um caso como no outro, o tempo de trabalho excedente aumenta relativamente ao tempo de trabalho necessário à reprodução da força de trabalho. A diferença, porém, é que no caso da mais-valia relativa se obtém esse resultado sem aumento dos limites da jornada de trabalho ou da sua mera intensificação e, ao mesmo tempo, sem a diminuição do montante de bens e serviços consumidos pela classe trabalhadora, enquanto, na mais-valia absoluta, o aumento do tempo de trabalho excedente resulta da redução desses bens e serviços incorporados na força de trabalho, ou do aumento real da jornada, ou ainda pela conjugação de ambos os processos. $\mathrm{O}$ resultado é o que Marx chamou de pauperismo, ao analisar a situação dos trabalhadores na Inglaterra no século XIX, condição esta que se repete ainda hoje pelo mundo todo.

Além disso, para melhor compreendermos a relação existente entre educação e desenvolvimento econômico, cabe destacar que na mais-valia relativa o aumento do tempo de trabalho excedente resulta da passagem do trabalho simples para o trabalho complexo, o qual equivale a um múltiplo do trabalho simples executado em idêntica fração de tempo, constituindo, portanto, um acréscimo de tempo de trabalho despendido, ou seja, de valor produzido.

Essa passagem do trabalho simples para o trabalho complexo só pode ocorrer mediante inovações tecnológicas, de tal forma que o acréscimo de valor produzido se conjuga com o aumento global da produtividade, diminuindo o valor de cada unidade produzida.

O que é importante destacar aqui é que apenas o acréscimo das qualificações decorrente de uma formação mais complexa do trabalhador permite a introdução de inovações e garante que se trabalhe eficazmente com elas, viabilizando os ganhos de produtividade.

Essa é a razão pela qual nos países ou regiões em que predominam os mecanismos da mais-valia relativa se observa um aumento da escolaridade e da complexificação dos processos formativos. A luta dos estudantes nesses países ou regiões por acesso a níveis de formação mais complexos e a bens culturais mais diversificados levou à expansão da matrícula dos níveis médio e superior de ensino e ao desenvolvimento acelerado da indústria cultural. Da mesma forma, a luta dos professores por melhores salários e condições de trabalho resultou no desenvolvimento das tecnologias de ensino, tendo em vista aumentar a produtividade do trabalho docente. 
Os capitalistas, por sua vez, têm interesse que a força de trabalho seja mais qualificada, pois isso lhes permite explorar também sua capacidade de raciocínio e criatividade.

Da confluência de todos esses fatores resultou o aumento da instrução geral, reforçando o papel da escola e do meio social no processo formativo das novas gerações de trabalhadores, em detrimento da família, já que a criança e o jovem em situação de mais-valia relativa são cada vez mais formados por especialistas e pelo próprio meio social em que se inserem.

Situação inversa observa-se onde predominam os mecanismos da mais-valia absoluta. Conforme referido anteriormente, como se trata apenas de estender a jornada de trabalho ou de intensificá-la sem nenhuma inovação tecnológica, o que ocorre é a mera intensificação ou aumento do trabalho simples. Nesse caso não há qualquer aumento da produtividade e o que se observa é um quadro de estagnação da economia e, inclusive, dos sistemas educativos.

Ao mesmo tempo, os baixos salários recebidos pelos pais levam os jovens a trabalhar mais cedo, afastando-os da escola, ou dificultando sobremaneira o processo de aprendizagem dos que conseguem frequentá-la. Disso resulta o comprometimento das qualificações de amplos segmentos da classe trabalhadora. Esses jovens, quando se inserem no mercado de trabalho, são capazes apenas de realizar trabalho simples. Além disso, as famílias situadas nas faixas de pobreza têm enormes dificuldades de formar e até de proteger seus filhos, embora seja exatamente sobre elas que recai a maior responsabilidade pela sua formação, já que as políticas sociais do Estado são precárias e os sistemas de ensino têm se mostrado inoperantes para esses segmentos mais pobres da população.

Dada a baixa capacitação tecnológica das economias baseadas nos mecanismos da mais-valia absoluta, os capitalistas não estão interessados em compensar essa baixa qualificação, pois operam com tecnologias convencionais, em geral, menos complexas. Daí a degradação do ensino nessas regiões e a importância atribuída à escola e à formação de professores serem praticamente nulas. Nesses países, o Estado tem garantido na lei, mas não na prática, formação básica para os trabalhadores. Daí serem os próprios jovens (alguns deles) a assumirem os custos de uma formação mais complexa, pagando-a por meio do assalariamento precoce.

Cabe ressaltar que não existe país ou região que opere apenas com uma dessas formas de exploração. Antes, elas existem articuladas, muitas vezes no interior de uma mesma cadeia produtiva. $\mathrm{O}$ que se pode dizer é que existem economias em que predominam uma ou outra forma com consequências bem distintas para o desenvolvimento econômico e para a reprodução da classe trabalhadora.

Nessa perspectiva, mesmo nas economias mais dinâmicas existem setores que utilizam formas convencionais de organização do trabalho e tecnologias menos complexas, recorrendo a uma força de trabalho capaz apenas de desempenhar trabalho simples. Esses setores, em geral constituídos por força de trabalho imigrante 
ou oriunda de regiões rurais tradicionais que habitam as periferias das grandes cidades, são explorados pelos mecanismos da mais-valia absoluta, vivendo grande parte no subemprego e em verdadeiros guetos. Esses guetos reproduzem-se no interior do sistema escolar mediante o fracasso escolar e a evasão de grande parte das crianças e dos jovens oriundos dessas famílias. Daí se ter verificado nas últimas décadas o aumento da escolaridade das novas gerações da classe trabalhadora em todo o mundo desenvolvido e, ao mesmo tempo, o crescimento do fracasso escolar e da evasão, de tal forma que parcela considerável de jovens se vê fora do sistema escolar antes mesmo de ter conseguido obter qualquer certificado.

De qualquer forma, durante todo o século XX, observamos a expansão do acesso de jovens a níveis crescentes de escolaridade em grande parte dos países ocidentais. O ritmo foi diferente em cada um deles, mas o processo seguiu até começar a atingir os níveis pós médio e superior no final do século XX.

\section{Universalização da educação, massificação e reprodução da classe trabalhadora}

Que o processo formativo no interior dos sistemas de ensino não tenha se reduzido a uma ação do capital, o atestam as incontáveis revoltas de estudantes e lutas de professores, especialmente a partir dos anos de 1960 nos Estados Unidos e Europa e, no Brasil, nos anos de 1980. Essas lutas, aliadas às novas exigências de qualificação e de um novo modelo disciplinar decorrente da reestruturação produtiva, levaram à crise da educação no mundo ocidental e obrigaram o capital a repensar o papel da escola e suas formas de funcionamento e regulação.

A universalização da educação escolar tem sido muitas vezes, na literatura educacional, denominada massificação. Cabe, no entanto, diferenciar um termo do outro. $\mathrm{O}$ primeiro diz respeito à expansão do acesso à educação escolar da quase totalidade das novas gerações de trabalhadores. Embora afirmado como um direito de todos nas chamadas democracias, a universalização tem resultado tanto do interesse dos capitalistas em explorar uma força de trabalho capaz de realizar atividades mais complexas e produtivas, quanto das pressões e lutas das famílias e dos jovens por acesso a níveis superiores de qualificação e aos certificados exigidos pelo mercado de trabalho.

A massificação, embora resultante da universalização, diz respeito à redução da educação às exigências estritas do mercado de trabalho tanto no que se refere aos conhecimentos por ele requeridos quanto à imposição da disciplina necessária às formas de organização do trabalho e de vida contemporâneos. A massificação, portanto, resulta da ação do capital para reduzir os processos formativos às exigências estritas da reprodução do capital, daí muitas vezes suscitar a apatia dos estudantes ou sua revolta contra os sistemas de ensino.

Com as remodelações do mercado de trabalho resultantes da reestruturação dos processos de trabalho, a composição social da classe trabalhadora foi bastante 
alterada. Houve uma aceleração do processo de proletarização de profissionais, cuja capacidade de trabalho não tinha sido até então subsumida à forma mercadoria. Refiro-me aos profissionais liberais, que eram donos de seu tempo de trabalho, controlavam as condições sob as quais exerciam suas atividades e se apropriavam do resultado do seu trabalho. Hoje esses profissionais são cada vez mais minoritários, pois a grande maioria é assalariada das empresas de saúde, de engenharia, de advocacia, estando submetidos à mesma racionalidade e controle tal como qualquer trabalhador dos setores tradicionalmente subordinados ao capital (Bruno, 1996).

Dessa forma, temos não só uma nova composição da classe trabalhadora como uma nova hierarquização em seu interior, regida por diferentes níveis de qualificação e pela posição que ocupam na cadeia de produção de valor (se são ou não trabalhadores estratégicos).

Essa nova hierarquização da classe trabalhadora reproduz-se no interior dos sistemas de ensino em âmbito mundial e está na base das reformas educacionais, inclusive do nível superior. O Processo de Bologna ${ }^{1}$, com a estratificação de cursos que instituiu em diferentes níveis de complexidade e duração, é a expressão dessa adequação do ensino superior à massificação desse nível de ensino.

Além disso, a globalização da economia levou à transnacionalização não só dos processos econômicos, mas das estruturas de poder do capitalismo. Isso fez com que a classe trabalhadora, e mais precisamente sua reprodução, passasse a ser pensada também neste nível, ou seja, supranacionalmente. A Conferência Mundial Sobre Educação Para Todos, realizada em 1990, em Jontien², enfatizando a necessidade de expandir o acesso à educação para as populações pobres, a importância conferida ao

1 O Processo de Bologna teve início em 1999 e hoje agrega 47 países, sendo 25 da União Europeia e 22 de outras regiões. O objetivo anunciado foi a necessidade de unificar um espaço europeu de educação superior, permitindo a circulação entre diversos países de trabalhadores com ensino superior, tanto no campo empresarial quanto acadêmico. Prevê a adoção de três ciclos $(3+2+4)$ - graduação, mestrado e doutorado; a obtenção de créditos acadêmicos que podem ser conseguidos por meio de cursos tradicionais, pela experiência de vida e de trabalho e a instauração de períodos semestrais, evitando a duplicação de recursos e facilitando a comparabilidade dos programas e diplomas obtidos nos diferentes países que assinaram o Acordo. Pressupõe alta padronização dos processos formativos com diferentes graus de complexidade e, segundo alguns de seus críticos, altera as formas tradicionais de financiamento da educação superior, já que abre espaço para o aumento das taxas escolares e para a venda de serviços nas formas de franchising, educação a distância, exportação de programas de pós-graduação, entre outros, reduzindo gradativamente o percentual do financiamento estatal das instituições de ensino.

2 Encontro de Jontien, ocorrido na Tailândia em 1990, seu objetivo era construir um consenso em âmbito mundial em torno de uma educação para todos com equidade social, tendo em vista enfrentar dois desafios: desenvolver uma educação que respondesse às novas exigências do setor econômico e atender às demandas das populações pobres (gestão da pobreza). 
papel da mulher na reprodução da força de trabalho nas regiões mais pauperizadas do mundo, a urgência em direcionar os processos educativos diretamente para o trabalho, a defesa da ação de novos agentes tanto na oferta quanto na regulação da educação em âmbito mundial, foi um marco na institucionalização de novas estratégias de reprodução da força de trabalho global.

Isso significa que a educação deixou de ser uma questão nacional e passou a ser pensada, planejada e regulada por centros de poder que vão muito além dos Estados Nacionais. A regulação da educação passou a envolver múltiplos agentes: além de agências multilaterais, associações empresariais, organizações transnacionais, também ONGs locais e internacionais, em geral, verdadeiros braços sociais das empresas.

As agências estatais inserem-se nessa estrutura de poder de forma subordinada, no geral, com seus órgãos operacionais. Daí serem elas o alvo mais imediato das revoltas e das reivindicações dos estudantes por melhores condições de ensino e pelo aumento dos investimentos estatais em educação, como se observa no Chile, atualmente. Ou seja, o Estado Nacional ainda é o mediador entre as populações locais e os centros de poder transnacionais.

O grande desafio para o capitalismo na contemporaneidade é como impor o trabalho enquanto controle social numa situação em que o capital se mundializou e o uso intensivo da maquinaria, da ciência e da tecnologia são redutores de trabalho vivo, aumentando o desemprego estrutural. Uma das saídas tem sido incorporar jovens sem emprego e desempregados, em geral, em atividades voltadas para a reprodução da classe trabalhadora, por meio do incentivo ao empreendedorismo individual, ao trabalho junto a comunidades carentes, à criação de cooperativas e empresas ditas autogestionárias, inseridas no que se deu o nome de Economia Solidária. Trata-se de um novo mecanismo de controle, na medida em que no capitalismo se efetiva por meio da imposição do trabalho a todos os que não possuem os meios de produção necessários à sua sobrevivência. "Impor o trabalho é conservar o controle social” (Cleaver, 1981, p. 111). Não por acaso, experiências de fábricas ocupadas e cooperativas surgidas da ação autônoma dos próprios trabalhadores tenham sido, na sua maioria, recuperadas pelo Estado e inseridas em políticas de governos na América Latina. As experiências de Banco do Povo, nas suas diversas versões em diferentes países, compõem igualmente essa nova estratégia de impor o trabalho, mantendo os trabalhadores sob controle por meio do crédito.

A educação, nesse contexto, teve de ser reformulada. A pedagogia das competências é a forma contemporânea de subordinar a aprendizagem às novas necessidades do capital, tanto no que se refere aos trabalhadores que atuam dentro das empresas quanto aos que trabalham fora dela, encarregando-se da reprodução da classe trabalhadora em diferentes âmbitos.

À medida que níveis mais complexos de escolaridade se abrem para segmentos mais amplos de trabalhadores, em razão de necessidades colocadas pelo 
desenvolvimento tecnológico e por todas essas mudanças no sistema capitalista, é necessário reformular os currículos, repensar a duração dos cursos de nível pós médio e mesmo superior, tendo em vista adequá-los à nova segmentação do mercado de trabalho e, ao mesmo tempo, demarcá-los relativamente aos cursos direcionados para a formação de gestores e de capitalistas.

O conhecimento a ser transmitido às novas gerações de trabalhadores em qualquer nível do ensino deve ser inteiramente instrumentalizado; é fundamental que o aluno saiba transformar o saber escolar em técnicas de trabalho e em comportamento adaptativo aos novos códigos disciplinares (ser proativo, saber resolver problemas no ambiente de trabalho e na comunidade, ser capaz de trabalhar sob pressão, assimilar as regras da competição imposta à classe trabalhadora). Sobre isso, um exemplo, entre tantos: um dos maiores grupos de educação superior do país, o Grupo Anhanguera, "direcionado aos jovens das classes C e D" (Folha de S.Paulo, 29 maio 2011) "que trabalham de dia e estudam à noite", tem em todos os seus cursos de graduação disciplinas como "desenvolvimento pessoal" e "responsabilidade social”, que vieram substituir disciplinas tradicionais como introdução à filosofia e metodologia científica. Como disse o fundador do grupo, em depoimento à reportagem do jornal acima referido: "Como se portar em entrevista e prática de leitura dinâmica são temas que a modernidade exigiu, não introdução a isso ou àquilo”.

Como se pode ver, ainda que a produção de capacidade de trabalho esteja exigindo mais anos de escolaridade e conhecimentos mais complexos, essa produção está longe de incluir o domínio de um pensamento teórico sólido e investigativo, ao contrário, trata-se apenas de garantir o aprendizado de conhecimento meramente instrumental e as competências trabalhadas são de caráter adaptativo às exigências do sistema. É esse, a meu ver, o sentido da massificação da educação, inclusive da superior. Essa massificação, portanto, não implica necessariamente universalização do acesso a todos os níveis de ensino num mesmo patamar de complexidade, pois se rege por uma lógica que lhe é própria.

\section{Valor de uso e valor de troca da educação}

Para analisar o valor de uso e o valor de troca da educação escolar e sua incidência no desenvolvimento econômico, vou abordá-la a partir da questão da qualificação, da qual constitui um dos elementos centrais. Há ainda muita discussão acerca do que seja qualificação, talvez pela dificuldade em estabelecer um sentido único a ela quando as formas de exploração do trabalho são muito distintas entre si, como ocorre no capitalismo contemporâneo. Em um artigo publicado em 1996, intitulado "Educação, qualificação e desenvolvimento econômico", apresentei uma formulação de qualificação, mais como recurso heurístico do que propriamente um conceito fechado. Considerei, então, qualificação como uma estrutura cujos elementos, além de mutáveis historicamente, se apresentam hierarquizados entre si a partir de uma determinada lógica, que por sua vez é dada pelas relações sociais 
de produção vigentes em processos de trabalho que são distintos entre si, do ponto de vista das formas de exploração. Historicamente a qualificação no capitalismo diz respeito à capacidade do trabalhador de realizar as tarefas requeridas pela tecnologia utilizada. Essa perspectiva pressupõe dois componentes básicos: um muscular e outro intelectual, que têm sido combinados de diferentes formas nas sucessivas fases do capitalismo.

Em termos históricos e em linhas muito gerais,

[...] desde que o capitalismo começou a se desenvolver em vastas regiões do mundo, a capacidade de trabalho do proletariado foi se caracterizando pela seguinte sucessão de etapas: inicialmente a qualificação dizia respeito à capacidade de realizar operações que requeriam grande esforço físico e habilidades manuais sempre mais aprimoradas. Depois, progressivamente, enquanto era obtido esse crescente adestramento muscular e manual, foram sendo desenvolvidos os componentes intelectuais da qualificação dos trabalhadores. O período que estamos vivendo se caracteriza exatamente pela predominância dos componentes intelectuais da capacidade de trabalho, especialmente daquela em processo de formação. Trata-se, pelos menos nos setores mais dinâmicos do capitalismo, de explorar não mais as mãos dos trabalhadores, mas seu cérebro. (Bruno, 1996, p. 92)

O que vem sendo valorizado pelas empresas que operam com tecnologias intensivas em conhecimento envolve pelo menos os seguintes elementos: escolaridade crescente; conhecimento tácito relacionado com a experiência subjetiva do trabalhador no exercício de sua função; capacidade de tomar decisões e prevenir desajustes operacionais; capacidade de comunicação que permita o estabelecimento de referências comuns e proposição de ações conjuntas entre trabalhadores que desempenham funções distintas e com diferentes graus de complexidade; habilidade manual que permita a utilização eficiente de equipamentos de alta precisão técnica; capacidade de inovação no âmbito das atividades desempenhadas; capacidade de selecionar e relacionar informações variadas; capacidade de assimilação de códigos e normas disciplinares e de comportamento, articulando, ainda, aspectos de personalidade e atributos relacionados à condição étnico-cultural, de gênero e geracional.

Esses elementos existem sempre articulados entre si e hierarquizados a partir de situações concretas, conferindo diferentes conteúdos à qualificação, consoante o processo de trabalho em questão, as condições conjunturais da economia, as estratégias patronais de utilização da força de trabalho e o nível de desenvolvimento das lutas dos trabalhadores.

Essa compreensão do que seja qualificação no capitalismo nos permite estudá-la nas mais diferentes situações, pois a cada hierarquização apresentada por seus elementos constitutivos temos uma dada configuração dos processos de 
exploração da capacidade de trabalho e uma dada valorização de alguns de seus elementos em detrimento de outros.

Isso situa a qualificação como algo decorrente diretamente das relações sociais de produção na sua contraditoriedade, isto é, a qualificação é aberta aos conflitos sociais. $\mathrm{Na}$ realidade, há sempre uma luta entre o trabalhador e a racionalidade que lhe é imposta por meio dos métodos de trabalho, da tecnologia empregada, da disciplina, da avaliação de seu desempenho, na medida em que se objetiva impedi-lo de usar sua capacidade de trabalho em benefício próprio.

Da mesma forma que o valor de uso e o valor de troca não são meras nomenclaturas, mas expressam posições de classe no interior da relação de exploração, a qualificação tem de ser vista desses dois pontos de vista.

Ser qualificado é, na perspectiva do capital, possuir algum tipo de capacidade de trabalho passível de ser utilizada na produção de valor, de mais-valia. Essa capacidade é, no capitalismo, uma mercadoria produzida socialmente por trabalhadores, como já foi referido anteriormente.

Uma mercadoria tem valor de uso porque tem um valor ao ser utilizada; ela satisfaz alguma necessidade socialmente dada. Possui também valor de troca quando não é imediatamente útil a quem a possui.

Para o capitalista, a capacidade de trabalho é valor de uso, pois será ele a explorá-la, tendo em vista a produção da mais-valia. Para o trabalhador, ela é valor de troca, pois não sendo proprietário dos meios de produção não pode utilizá-la em benefício próprio, tendo de vendê-la ao capitalista para garantir sua sobrevivência.

Dessa forma, o valor de uso e o valor de troca da força de trabalho são evidentemente contraditórios. Porém, se para o capitalista ela é valor de uso quando este a compra e a põe para trabalhar, a questão não se encerra aí. Como diz Cleaver (1981), o capitalista também tem de preocupar-se com o valor de troca da força de trabalho, já que está interessado na mais-valia, que está relacionada ao valor que deverá ser destinado à sobrevivência do trabalhador. Em consequência, o seu interesse é reduzir ao máximo esse valor de troca.

Para o trabalhador, por sua vez, sua capacidade de trabalho, além de ser para ele valor de troca, é também valor de uso, como dito anteriormente, quando ele se organiza para lutar contra a exploração, por melhores condições de trabalho e de vida; quando utiliza sua capacidade de pensar e de se organizar em seu próprio benefício. Daí as lutas autônomas dos trabalhadores serem as únicas que desafiam a forma mercadoria que define a força de trabalho no capitalismo. O que quero ressaltar aqui é que as diferentes perspectivas de classe acerca do valor de uso e do valor de troca não são fixas nem tão evidentes (Cleaver, 1981).

Da mesma forma, podemos pensar a qualificação decorrente da formação escolar. Vejamos primeiramente como se coloca essa questão do ponto de vista do capital. A qualificação, isto é, a capacidade de trabalhar, é valor de uso para o 
capitalista, pois é ele quem irá explorá-la. No capitalismo o real consumidor da qualificação da força de trabalho é o capital, já que para o trabalhador ela é mercadoria alienável, valor de troca. Daí ser do interesse do capitalista controlar os processos formativos, que devem produzir capacidade de trabalho dentro de certos padrões exigidos pela organização do trabalho e pela tecnologia utilizada, o que envolve conhecimento e disciplina.

Mas, além disso, como o valor da força de trabalho é dado pelo tempo de trabalho socialmente necessário para a sua produção e reprodução, os processos formativos e, portanto, a educação escolar, devem estar sob o controle estrito do capital, também por outra razão. É fundamental garantir o aumento permanente da produtividade do trabalho nessa esfera, tendo em vista compensar o aumento não só dos anos de escolaridade, mas também da complexidade dos processos formativos exigidos pelo desenvolvimento tecnológico.

Caso a produtividade dos processos escolares seja baixa, o valor da força de trabalho será, a cada geração, crescente, o que incidirá de forma negativa no montante de mais-valia produzida pelas novas gerações.

Nesse sentido, podemos entender por que o controle do capital sobre os processos formativos é maior hoje do que o foi há trinta anos. Esse aumento é visível e claramente sentido não só pelos estudantes como também pelos professores. A utilização crescente da tecnologia digital, a produção de material didático padronizado, as avaliações permanentes, assim como a produção em massa de professores com nível superior, em tese, capazes de trabalho mais complexo, visam reduzir o valor da força de trabalho em processo de formação.

Da mesma forma, como bem formulou Cleaver (1981, p. 142), "Quanto mais trabalho os alunos realizam na escola, menor o valor que deve ser investido no seu treinamento e disciplina, tanto para a realização do trabalho na empresa quanto no âmbito da família ou de qualquer outra esfera de produção de capacidade de trabalho". Nesse sentido, pode-se dizer que um aumento na produtividade do trabalho escolar, tanto do aluno quanto do professor, reduzindo o volume de capital variável necessário à formação das novas gerações de trabalhadores, pode contribuir para a expansão da mais-valia, ou, inversamente, uma redução do trabalho de ambos pode comprometer essa expansão.

Isso nos permite compreender por que gestores da educação e capitalistas estão sempre denunciando a falta de dedicação do professor ou a rebeldia do estudante como elementos responsáveis pelos resultados decepcionantes dos processos de aprendizagem no Brasil. Esse discurso é muito semelhante ao de F. W. Taylor no início do século XX, quando acusava os trabalhadores de serem preguiçosos e de não utilizarem toda a sua capacidade de trabalho no desempenho de suas tarefas.

Por essa razão, novas formas de organização e controle do trabalho escolar são instituídas, envolvendo alunos e professores num novo quadro disciplinar. Mas não só a educação a distância, que vem sendo cada vez mais utilizada nos processos 
formativos, constitui um novo passo na busca do aumento da produtividade do trabalho escolar. Nesse caso, o esforço do aluno deve ser ainda maior, pois estará trabalhando na sua própria qualificação, em grande parte sozinho e com pouca interferência do professor. $\mathrm{O}$ trabalho desse profissional, por sua vez, pode atingir um número extraordinário de alunos, em diferentes espaços físicos e em diversos momentos, com o auxílio da tecnologia digital. Os ganhos de produtividade que se busca alcançar são muito maiores do que tudo o que se conheceu até hoje.

Essas inovações, da mesma forma que a massificação, estão associadas ao aumento da escolaridade e da complexidade dos processos formativos da classe trabalhadora. Embora o conhecimento deva ser transmitido a conta-gotas, consoante os diferentes graus de exigência dos postos de trabalho disponíveis tanto no interior das empresas quanto fora delas (no âmbito da reprodução da classe em sentido lato), não há dúvida de que, durante todo o século XX, houve um acréscimo geral das qualificações dos trabalhadores. Consequentemente, o aumento da produtividade dos processos formativos passou a ser uma questão de sobrevivência do capitalismo, tendo em vista reduzir o valor da reprodução da classe trabalhadora, especialmente das novas gerações. E essa exigência abarca todos os níveis de ensino e os processos formativos mesmo dos trabalhadores altamente qualificados, embora, nesses casos, o recurso aos mecanismos da mais-valia absoluta, especialmente à mera redução dos custos formativos, seja secundarizado em benefício da qualidade do ensino.

Dessa forma, como no capitalismo as desigualdades são elementos constitutivos de sua estrutura, as diferenciações no interior da classe trabalhadora, quanto a salários, condições de vida e qualificação, não desapareceram, ao contrário, podem até terem se agravado. A razão é que, do ponto de vista do capital, seria um desperdício formar a totalidade das novas gerações num mesmo grau de complexidade. Com a dinâmica do mercado de trabalho formal, altamente estratificado e poupador de força de trabalho, muitos jovens jamais serão inseridos neles. Eles irão para o exército de reserva ou executarão trabalhos simples que não exigem o mesmo grau de complexidade dos trabalhos voltados para a produção de inovação e para a produção de mercadorias com alto valor agregado.

Por conseguinte, a formação de amplos segmentos da classe trabalhadora parece reduzir-se, atualmente, à mera tentativa de impor trabalho aos alunos, tendo em vista assegurar o controle social sobre essas jovens populações potencialmente explosivas do ponto de vista social. Quando se diz que a escola não ensina, ou ensina muito pouco para essas populações, talvez tenhamos de reconhecer que nem toda escola no capitalismo contemporâneo existe primordialmente para ensinar, existe antes para disciplinar e controlar comportamentos. Mas, mesmo nesses casos, uma produtividade crescente é necessária.

Da mesma forma que a geladeira deixou de ser um bem de luxo presente apenas nas casas burguesas e passou a fazer parte dos lares de trabalhadores (aumentando a produtividade do trabalho doméstico), em decorrência das inovações 
tecnológicas que reduziram o tempo de trabalho socialmente necessário para a sua fabricação, a educação deixou de ser privilégio dos filhos das famílias de capitalistas, gestores e profissionais liberais, para constituir-se um processo geral de produção de capacidade de trabalho e de controle social. A reorganização, do trabalho escolar que hoje se observa em todo o mundo, e cujas diretrizes emanam de organizações supranacionais, indica a premência dessa reorganização tendo em vista reduzir o tempo de trabalho necessário para a formação das novas gerações de trabalhadores em qualquer nível de escolaridade e complexidade.

Penso que as dificuldades para se chegar a um resultado razoável quanto aos ganhos de produtividade no setor educacional têm levado os mais diferentes Estados Nacionais, mas especialmente o brasileiro, a compensar essa limitação recorrendo à simples redução dos custos formativos.

Intensificar o trabalho do professor, aumentar a jornada e reduzir o valor da sua força de trabalho por meio de baixos salários, são mecanismos típicos da mais-valia absoluta. Historicamente, isso gera apatia e desinteresse dos docentes por seu trabalho, o que, por sua vez, agrava o quadro de baixa produtividade e compromete ainda mais a qualidade do ensino, impedindo o recurso à mais-valia relativa, num círculo vicioso que só agrava o quadro geral.

O que se denomina hoje, no Brasil, degradação do ensino é, em pelo menos um aspecto, a dificuldade de se obterem ganhos de produtividade na forma atual de organização do ensino, tendo de se recorrer à mera redução de custos. A própria formação de professores, embora realizada por meio de um aumento da escolaridade (ensino superior), não tem conseguido alterar esse quadro.

A forma como esta vem sendo conduzida, isto é, obedecendo aos mecanismos da mais-valia absoluta, com a precarização do trabalho docente universitário, principalmente nas instituições de ensino privadas, baixos salários, extensas jornadas de trabalho, número excessivo de estudantes em sala de aula, ausência de formação teórica e em pesquisa e educação a distância na formação inicial tem comprometido a formação das novas gerações de professores, impedindo a passagem do trabalho simples para o trabalho complexo no âmbito dos processos formativos.

Daí o fato de os investimentos realizados em educação no Brasil nas últimas décadas não terem alterado o quadro de estagnação ou até mesmo de degradação dos processos educacionais, exatamente quando qualificações mais complexas começam a ser exigidas pela inserção da economia brasileira nos centros mais dinâmicos de acumulação de capital.

Do ponto de vista do trabalhador, o valor de troca da educação está relacionado com o valor que suas aptidões adquiridas durante o processo formativo têm no mercado de trabalho, seja ele formal ou informal. Esse valor, por sua vez, decorre do tempo de trabalho neles incorporado durante seus processos formativos por todos aqueles que nele contribuíram. Mas não só, como já disse Marx, a força de trabalho é a única mercadoria cujo valor se estabelece também a partir de lutas 
sociais. Categorias mais organizadas, com maior capacidade de luta, tendem a ver seu valor aumentado relativamente a outras que não possuem essa capacidade.

Além disso, há a própria dinâmica da economia que incide sobre esse valor. Quando se inaugura um novo patamar tecnológico e um ciclo da mais-valia relativa se inicia, os trabalhadores formados em patamares tecnológicos anteriores sofrem uma desvalorização aguda. Da mesma forma, períodos de recessão econômica, em geral, empurram para o desemprego e/ou para o subemprego trabalhadores altamente qualificados, em decorrência da redução dos postos de trabalho, o que implica a desvalorização de sua capacidade de trabalho pela sua subutilização.

Todas essas situações não passam despercebidas para as novas gerações, que muitas vezes não veem razões suficientes para se submeterem aos processos de aprendizagem, tendo em vista o futuro que os espera. Da mesma forma, com a percepção de que a inserção no mercado de trabalho está vinculada ao que Bourdieu denominou capital social, muitos jovens das famílias de trabalhadores não esperam galgar posições mais altas nas hierarquias das empresas, apesar de serem portadores de certificados, pois lhes falta esse elemento.

A meritocracia, que teve um papel importante durante o século XX na busca de mais escolarização e formação em geral, está hoje bastante comprometida, não só pela redução do emprego, mas também pelo fato de a chamada democratização do ensino ter assumido a forma de uma democratização segregativa (Duru-Ballet, 2006), consoante a segmentação do mercado de trabalho e a origem de classe dos estudantes. Se há algumas décadas a escola era vista como via de ascensão para os jovens das famílias de operários e trabalhadores rurais que, após anos de estudo, iam inserir-se em atividades do setor de serviços e nas burocracias privada e estatal, vistas como atividades menos penosas e mais prestigiadas que a de seus pais, hoje, com a assimilação dos critérios de produtividade e eficiência por esses setores, a ideia de ascensão e melhoria de vida evaporou-se. A escola perdeu, assim, muito de sua atração.

Daí estarmos observando, especialmente nas escolas estatais dos bairros mais pauperizados das grandes cidades, um vasto processo de sabotagem ao ensino por parte dos estudantes. Eles negam-se tanto a aprender o que a escola seleciona como relevante para a sua formação, quanto a se submeter à disciplina escolar. $\mathrm{Na}$ realidade, negam-se a trabalhar na sua formação, pois o valor de troca de sua força de trabalho, que calculam a partir da situação das gerações mais velhas, não lhes parece atraente o suficiente para que se submetam aos processos de aprendizagem, já que o futuro que se lhes afigura é o mesmo de seus pais e vizinhos, e até mesmo de seus professores, vistos como mal pagos, desprestigiados e sufocados por um ritmo de trabalho estafante.

Os professores, por sua vez, na atual organização hierárquica da escola, estão situados entre os alunos e os vários níveis da administração que representa o poder. Pela posição que ocupam, são instados a atuar como mediadores entre ela e 
os estudantes, mas as suas dificuldades em impor disciplina a alunos que se negam a permanecer sentados e trabalhando são evidentes. Como os professores foram privados do uso da avaliação como instrumento de controle e punição, posto que agora esta foi deslocada para órgãos mais centrais, e como sua autoridade profissional está bastante fragilizada pelas novas formas de gestão que lhes retira a iniciativa e a autonomia, subordinando-os a diretrizes centrais, só resta à instituição escolar recorrer à presença das forças de segurança, a uma arquitetura cada vez mais próxima da prisional e a práticas sempre mais repressivas. Isto, por sua vez, induz os estudantes a mais sabotagem e violência, num ciclo que está longe de ser quebrado.

Nesse ciclo, a violência dos alunos, em vez de se direcionar contra a administração enquanto representante do poder, tem sido dirigida contra os professores e até mesmo contra outros estudantes.

Os professores enfrentam, de um lado, a inoperância de seus sindicatos, que se encontram inteiramente burocratizados e vinculados aos centros de poder estatal, mostrando-se incapazes de apoiar qualquer luta em defesa de seus interesses, e, de outro, têm de enfrentar as dificuldades de se auto-organizar numa situação de fragmentação da categoria em virtude das diferenciações nas situações de trabalho (temporários, estáveis), das políticas de gratificação por desempenho baseadas em critérios discutíveis de eficiência e produtividade, além da dispersão da jornada de trabalho por mais de uma instituição escolar. Diante de tais obstáculos, parece predominar entre grande parte dos professores a indiferença, a apatia e formas de resistência individual no ambiente de trabalho, que em nada alteram o quadro de suas dificuldades, mas incidem diretamente sobre a qualidade dos processos formativos das novas gerações.

Da mesma forma, a resistência e a sabotagem dos estudantes à escola, nos moldes em que vem ocorrendo, embora seja a expressão da negação de um futuro do qual querem escapar, isto é, do desemprego, do subemprego, dos baixos salários e da submissão, acabam por voltar-se contra eles próprios, na medida em que acarretam sua desvalorização antes mesmo de ingressarem no mercado de trabalho. Muitos desses jovens estão condenados a viver e a morrer fora do mercado de trabalho formal e das formas de consumo a que têm acesso as camadas mais qualificadas e produtivas da classe trabalhadora. Talvez por isso lhes seja tão importante se organizar em grupos ou gangues, rejeitando todas as formas de disciplina, controle e integração social que não tenham sido estabelecidas por eles próprios.

Finalmente, essa situação geral da educação no Brasil representa, do ponto de vista do capital, um verdadeiro colapso do seu controle sobre a produção de capacidade de trabalho, comprometendo o processo de crescimento econômico na sua base. Do ponto de vista dos alunos e dos professores, trata-se de uma situação na qual não conseguem tomar para si a condução desse processo e transformar em valor de uso suas capacidades, fazendo-as reverter-se em benefício próprio.

Nesse sentido, a linearidade entre investimentos em educação e desenvolvimento econômico, estabelecida pela Teoria do Capital Humano, fica comprometida 
na base da própria formulação em que se apresenta. Para compreender-se essa relação, é necessário considerar a dimensão política da educação, tanto na sua forma de controle do capital sobre a reprodução da força de trabalho global, quanto na forma das resistências e lutas dos estudantes e professores a esse controle e as formas por ele assumidas.

\section{REFERÊNCIAS}

BRuno, Lúcia. Educação, qualificação e desenvolvimento econômico. In: BRUNO, L. (Org.). Educação e desenvolvimento econômico. São Paulo: Atlas, 1996.

BERnARDo, João. O trabalhador como produto e como produtor. Revista de Economia Política, FGV, São Paulo, vol. 5, n. 3, jul./set. 1985.

Cleaver, Harry. Leitura politica do Capital. Rio de Janeiro: Zahar, 1981.

Duru-Ballet, Marie. L'inflation scolaire: les désilusions de la méritocratie. Paris: Éd. du Seuil; La Republique des Idées, 2006.

FOLHA de S.Paulo, 29 maio 2011. Caderno B (Mercado) p.7.

Marx, Karl. El Capital. México, Fondo de Cultura Econômica, 1976.

Tronti, Mario. Social Capital. Telos, 17, 1973.

\section{SOBRE A AUTORA}

LÚCIA BRUNO é doutora em sociologia pela Universidade de São Paulo (USP). Professora livre-docente da mesma instituição. E-mail: lenuevo@usp.br 


\section{RESUMOS/ ABSTRACTS / RESUMENS}

\section{LÚCIA BRUNO}

\section{Educação e desenvolvimento econômico no Brasil}

$\mathrm{O}$ artigo discute as relações existentes entre educação e desenvolvimento econômico, recorrendo à Lei do Valor formulada por Marx. Nessa perspectiva, aborda a formação das novas gerações, inserido-a no âmbito mais vasto da produção e reprodução da força de trabalho, em situações de mais-valia absoluta e de mais-valia relativa. As mudanças no campo educacional são referidas como a tentativa de inaugurar uma nova etapa nesse processo, a partir da reorganização do capitalismo iniciada nos anos de 1980. Questiona a linearidade afirmada na Teoria do Capital Humano entre educação e desenvolvimento econômico, integrando na análise aspectos políticos relativos às lutas e à recusa de estudantes a aprender o que a escola seleciona como relevante, assim como a resistência dos professores às formas de trabalho a que estão submetidos.

Palavras-chave: reprodução da classe trabalhadora; massificação da educação; valor de uso e valor de troca da educação

\section{Education and economic development in Brazil}

This article discusses the relationship between education and economic development, considering Marx's Law of Value. From this perspective, it analyzes the education of new generations, inserting this process in the vast realm of production and reproduction of the labor force, in situations of absolute and relative surplus value. Changes in education are seen as attempts to inaugurate a new phase in this process, based on the reorganization of capitalism inaugurated in the 1980s. The article questions the linearity between education and economic development affirmed by the Theory of Human Capital, integrating to the analysis political aspects related to the struggles and refusal of students to learn what the school selects as relevant, as well as resistance of teachers to the forms of labor to which they are submit.

Keywords: reproduction of the working class; mass scale education; use value and exchange value of education.

\section{Educación y desarrollo económico en Brasil}

El artículo discute las relaciones existentes entre la educación y el desarrollo económico, recurriendo a la Ley del Valor formulada por Marx. En esta perspectiva, se aborda la formación de las nuevas generaciones incluyéndola en el ámbito más vasto de 
la producción y reproducción de la fuerza de trabajo, en situaciones de plusvalía absoluta $y$ de plusvalía relativa. Las mudanzas en el campo de la educación son referidos como la tentativa de inaugurar una nueva etapa en este proceso, a partir de la reorganización del capitalismo inaugurada en los años ochenta. Cuestiona la linealidad afirmada en la Teoría del Capital Humano entre la educación y el desarrollo económico, integrando en el análisis aspectos politicos relativos a las luchas y al rechazo de estudiantes a aprender lo que la escuela selecciona como relevante, asi como la resistencia de los profesores a las formas de trabajo a que están sometidos.

Palabras clave: reproducción de la clase trabajadora; masificación de la educación; valor de uso del cambio de la educación.

\section{PAULO ROBERTO CORBUCCI}

\section{Dimensões estratégicas e limites do papel da educação para o desenvolvimento brasileiro}

O propósito maior deste estudo é o de discutir a relação entre educação e desenvolvimento no contexto atual da sociedade brasileira, tendo-se em conta a condição sistêmica de uma economia altamente globalizada. Parte-se da premissa segundo a qual o desenvolvimento não é factível a todos os países, ao menos nos padrões alcançados no chamado Primeiro Mundo, mas também se reconhece que o desenvolvimento de uma nação não se concretiza sem uma educação de qualidade para todos. Questiona-se o poder de transformação social que tem sido atribuído à educação, uma vez que ela própria é, em grande medida, derivada das condições socioeconômicas. Busca-se analisar em que grau o padrão educacional brasileiro estaria comprometendo o desenvolvimento do país e como este, em seu estágio atual, afeta a qualidade da educação. Trata-se, pois, de analisar potencialidades e limites da educação diante do desafio de tornar o Brasil uma nação economicamente dinâmica e socialmente justa.

Palavras-chave: educação e desenvolvimento; relação centro-periferia; fatores socioeconômicos.

\section{Strategic dimensions and limits of the role of education for brazilian development}

The main purpose of this study is to discuss the relationship between education and development in the current context of Brazilian society, taking into account the systemic condition of a bighly globalized economy. It starts with the premise that development is not feasible for all countries, at least in the standards achieved in the so-called First World, but also recognizes that the development of a nation is not realized without a quality education for all. Place under discussion the power of social transformation that has been attributed to education, since it is itself largely derived from socioeconomic conditions. Seeks 